\title{
Intraoperative hyperthermic chemotherapy perfusion for malignant pleural mesothelioma: An in vitro evaluation
}

\author{
Robert B. Cameron, $\mathrm{MD},{ }^{\mathrm{a}}$ and Dongmei Hou, $\mathrm{PhD}^{\mathrm{b}}$
}

Objectives: Hyperthermic chemotherapy perfusion has been used in the treatment of both pleural and peritoneal mesothelioma without an extensive basic science foundation. Clinical data are limited with no prospective randomized trials to support the use of this potentially toxic therapy. We sought to generate basic scientific support for this clinical practice and to define the optimal conditions for use in future clinical trials.

\begin{abstract}
Methods: Growth of a variety of in vitro established cell lines, including a hyperthermia-sensitive Chinese hamster ovary (CHO)-K1 cell line, a normal lung fibroblast line (MRC-5), a lung cancer line (A549), and 3 human mesothelioma cell lines (NCI-H28, NCI-H2052, and MSTO-211H), was assessed using a novel tetrazolium compound (3-(4,5-dimethylthiazol-2-yl)-5-(3-carboxymethoxyphenyl)-2-(4-sulfophenyl)-2H-tetrazolium, inner salt [MTS]) and an electron coupling reagent (phenazine methosulfate), which measures the absorbance at $490 \mathrm{~nm}$ of a formazan product reduced from MTS by living cells (MTS metabolic assay), or a standard dilution clonogenic assay, which enumerates colony-forming units of more than 50 cells. Each cell line was plated into flasks and then exposed to varying combinations of chemotherapy agents and hyperthermia $\left(37^{\circ} \mathrm{C}-45^{\circ} \mathrm{C}\right)$. The cells then were harvested and assessed in either assay. The role of chemotherapeutic agents currently most commonly used in clinical practice, including cisplatin, gemcitabine, and pemetrexed, was assessed with and without simultaneous heat exposure.
\end{abstract}

Results: Conditions initially were explored using hyperthermia alone in CHO-K1, A549, and NCI-H28 cell lines using temperatures of $37^{\circ} \mathrm{C}, 42^{\circ} \mathrm{C}$, and $45^{\circ} \mathrm{C}$ for 20,40 , and 60 minutes, respectively. This showed a reproducible dose-response curve in $\mathrm{CHO}-\mathrm{K} 1$ cells with increasing temperature producing lower survival to only $1.5 \%$ of the control at $45^{\circ} \mathrm{C}$ for 60 minutes $(P<.01)$. The A549 cells also showed a response but only at the highest temperature, and the NCI-H28 cells showed a more modest reduction to $65 \%$ at $45^{\circ} \mathrm{C}$ for 60 minutes $(P<.01)$. When the 2 assays were directly compared, the MTS assay failed to detect differences between groups and therefore was discontinued from the remainder of these experiments. Next, hyperthermia was limited to the physiologic limit of $42^{\circ} \mathrm{C}$, and the addition of chemotherapy was assessed. Doses were chosen on the basis of prior pharmacokinetic data from studies showing a maximum tissue/blood level of $200 \mathrm{ng} / \mathrm{mL}$ for cisplatin pleural instillation and were thought to more accurately reflect actual tumor levels. Cisplatin alone modestly reduced the clonogenic potential to $26 \%, 16.4 \%$, and $13.6 \%$ at $42^{\circ} \mathrm{C}$, respectively, for 60 minutes $(P<.01)$; however, this was only a further reduction of $29.6 \%, 33.8 \%$, and $34.2 \%$, respectively, from the cisplatin alone control. Therefore, most of the reduction was attributable to chemotherapy and not hyperthermia. With combinations of cisplatin/gemcitabine and cisplatin/pemetrexed, the effect was larger, with reduction to $9.6 \%, 0 \%$, and $0 \%$, respectively $(P<.01)$ (incremental reduction of $16.5 \%, 0 \%$, and $0 \%$, respectively, due to hyperthermia). Cisplatin/pemetrexed produced essentially identical results.

Conclusions: Intrapleural chemotherapy seems to be most effective when using 2 drug combinations. All mesothelioma cell lines showed no particular sensitivity to heat. The use of hyperthermia alone or with chemotherapy produces at best only a modest effect and does not necessarily support its current clinical use. (J Thorac Cardiovasc Surg 2013;145:496-504)

Malignant mesothelioma is one of only a few human tumors that uniformly present as a diffuse primary malignant process rather than a solid localized mass. This fact makes

From the Severin Wunderman Division of Thoracic Surgery, ${ }^{\mathrm{a}}$ David Geffen School of Medicine at UCLA, Los Angeles, Calif; and Punch Worthington Research Laboratory, ${ }^{\mathrm{b}}$ Department of Surgery, David Geffen School of Medicine at UCLA, Los Angeles, Calif.

Funding: This work was supported in part by the Pacific Heart, Lung, \& Blood Institute.

Disclosures: Dr Cameron serves as an unpaid Scientific Advisor for the Pacific Heart, Lung, \& Blood Institute. Dr Hou has nothing to disclose with regard to commercial support. mesothelioma difficult to approach surgically; however, surgery still can play an important role within a multimodality treatment program if other effective adjuvant therapies are

Read at the 38th Annual Meeting of The Western Thoracic Surgical Association, Maui, Hawaii, June 27-30, 2012.

Received for publication June 25, 2012; revisions received Sept 24, 2012; accepted for publication Oct 22, 2012; available ahead of print Nov 21, 2012.

Address for reprints: Robert B. Cameron, MD, Room 64-128 CHS, David Geffen School of Medicine at UCLA, Box 957313, 10833 Le Conte Ave, Los Angeles, CA 90095-7313 (E-mail: rcameron@mednet.ucla.edu).

$0022-5223 / \$ 36.00$

Copyright (c) 2013 by The American Association for Thoracic Surgery http://dx.doi.org/10.1016/j.jtcvs.2012.10.042 


\section{Abbreviations and Acronyms \\ $\mathrm{CHO}=$ Chinese hamster ovary \\ MTS $=3$-(4,5-dimethylthiazol-2-yl)- \\ 5-(3-carboxymethoxyphenyl)- \\ 2-(4-sulfophenyl)-2H-tetrazolium, \\ inner salt}

available. Hyperthermia, particularly within the context of intracavitary (intrapleural or intraperitoneal) administration, is one such adjuvant therapy candidate. The treatment of cancer by heat has a long history, and reports of hyperthermia and mesothelioma date at least to the early 1970s. ${ }^{1}$ Woo and colleagues $^{2}$ were the first to report a possible mesothelioma sensitivity to hyperthermia in a fresh mesothelioma biopsy specimen. Others have reported a selectivity of hyperthermia for cancer cells in general. ${ }^{3}$ For decades, clinicians have evaluated hyperthermia in numerous clinical protocols, ${ }^{4-7}$ yet level I/II data defining and supporting its role remain elusive.

Although there is a reasonable body of basic biology research in the field of hyperthermia and cancer, relatively little data exist specifically regarding malignant mesothelioma. Mesothelioma, melanoma, and ovarian cancer are the 3 most common malignancies with a history of treatment with hyperthermia. Although limb perfusion for melanoma and intraperitoneal hyperthermic chemotherapy for ovarian cancer have been somewhat systemically studied, the use of hyperthermia in malignant mesothelioma has defied standardization. Variables in the clinical use of hyperthermia for mesothelioma include (1) hyperthermic temperature, ranging primarily from $41^{\circ} \mathrm{C}$ to $43^{\circ} \mathrm{C}$ (rarely higher); (2) delivery method, which most often has used a cardiopulmonary bypass perfusion circuit; (3) specific chemotherapy, which has varied from doxorubicin to mitomycin, cytarabine, and bleomycin, and more recently to cisplatin, oxaliplatin, or even a combination of agents; and (4) exposure time, which has been up to 120 minutes but most often does not exceed 1 hour. Without detailed background information on the optimal conditions to be incorporated in planning clinical trials, we decided to define the specific parameters for the use of hyperthermia in the treatment of mesothelioma by investigating the various factors in vitro.

\section{MATERIALS AND METHODS Cell Lines}

In vitro established cell lines, including a hyperthermia-sensitive Chinese hamster ovary ( $\mathrm{CHO})-\mathrm{K} 1$ cell line, a normal human lung fibroblast line (MRC-5), a human lung cancer line (A549), and 3 human mesothelioma cell lines (NCI-H28, NCI-H2052, and MSTO-211H), were obtained from the American Type Culture Collection (Manassus, Va) and cultured in $75 \mathrm{~cm}^{2}$ Vent Cap Greiner Tissue Culture Flasks (E\&K Scientific, Santa Clara, Calif). NCI-H28, NCI-H2052, and MSTO-211H were cultured in Roswell Park Memorial Institute 1640; MRC-5 was cultured in Eagle's Minimum Essential Medium; and CHO-K1 was cultured in F12-K media
(American Type Culture Collection) supplemented with $10 \%$ fetal bovine serum (Thermo Fisher Scientific, Pittsburgh, Pa) and antibiotics in a humidified incubator at $37^{\circ} \mathrm{C}$ with $5 \% \mathrm{CO}_{2}$.

\section{Hyperthermia}

Cell lines were plated into 6-, 12-, or 96-well plates (Corning Inc, Tewksbury, Mass) at a density of approximately $1 \times 10^{5}$ cells $/ \mathrm{mL}$, depending on the planned type of assay, and allowed to adhere for 24 hours before treatment. The cells were treated during the exponential growth phase. After 24 hours, plates were treated in water baths at $37^{\circ} \mathrm{C}, 42^{\circ} \mathrm{C}$, or $45^{\circ} \mathrm{C}$ for 0 to 60 minutes. After treatment, the spent media were replaced with $3.0 \mathrm{~mL}$ of fresh media, and the plates were cultured at $37^{\circ} \mathrm{C}$ for an additional period of time before being assessed by the 3-(4,5-dimethylthiazol-2-yl)-5-(3-carboxymethoxyphenyl)2-(4-sulfophenyl)-2H-tetrazolium (MTS) or clonogenic assay.

\section{Chemotherapy}

Chemotherapeutic agents commonly used with mesothelioma were cisplatin (Sigma Aldrich, St Louis, Mo), which was diluted in dimethyl sulfoxide, and gemcitabine and pemetrexed (Eli Lilly, Indianapolis, Ind), which were diluted in water.

All drugs were handled with personal protective equipment and diluted in media to the desired concentrations for use in the experiments. After use, all chemotherapy media and equipment were disposed in an approved biohazard container.

\section{MTS Assay}

The MTS assay consists of a tetrazolium compound (MTS) and an electron coupling reagent (phenazine methosulfate). The assay measures metabolic activity as a surrogate for cell viability. For this assay, $1.0 \times 10^{4}$ cells/well were seeded into 96-well microplates (Corning Inc) and incubated in a humidified incubator at $37^{\circ} \mathrm{C}$ with $5 \% \mathrm{CO}_{2}$ to allow cell attachment. At the time of the assay, the spent media were replaced with $100 \mu \mathrm{L}$ of fresh media plus $20 \mu \mathrm{L}$ MTS/phenazine methosulfate solution (Promega, Madison, Wis), and the plates were incubated for another 4 hours in a humidified incubator at $37^{\circ} \mathrm{C}$ with $5 \% \mathrm{CO}_{2}$. The absorbance of formazan reduced from MTS by metabolically active cells was measured at a wavelength of $490 \mathrm{~nm}$ using the ELx80 microplate reader (BioTek Instruments, Inc, Winooski, Vt). All assays were performed in triplicate, and the results are expressed as a mean \pm standard error.

\section{Clonogenic Assay}

A standard clonogenic assay was performed to enumerate colonyforming units of more than 50 cells. Cells from each cell line were placed at a density of 100 to 500 cells/well in triplicate into 6-well plates (Corning $\mathrm{Inc}$ ) and incubated in a humidified incubator at $37^{\circ} \mathrm{C}$ with $5 \% \mathrm{CO}_{2}$ for 24 hours to allow the cells to adhere. After treatment with hyperthermia, the spent media were replaced with $3.0 \mathrm{~mL}$ of fresh media at $37^{\circ} \mathrm{C}$ and cultured for 10 days in a humidified incubator at $37^{\circ} \mathrm{C}$ with $5 \% \mathrm{CO}_{2}$. Media were removed, and the cells were washed with $1 \times$ phosphate-buffered solution (Thermo Fisher Scientific). The colonies were fixed and stained with $2 \%$ methyl blue (Sigma Aldrich) in methanol for 20 minutes. The plates were washed with water to remove the remaining methyl blue and air dried. Colonies containing 50 or more cells were counted. Plating efficiencies and survival fractions were calculated from the ratio of the number of colonies formed to the control numbers of cell plated. All assays were performed in triplicate, and the results are expressed as a mean \pm standard error.

\section{Statistical Analysis}

Treatment group means \pm standard error were compared using MedCalc software version 12.2.1.0 (MedCalc Software bvba, Mariakerke, Belgium), and $t$ tests, assuming equal variance, were performed on groups with significance levels calculated by a 2 -tailed $P$ value less than .001 . 


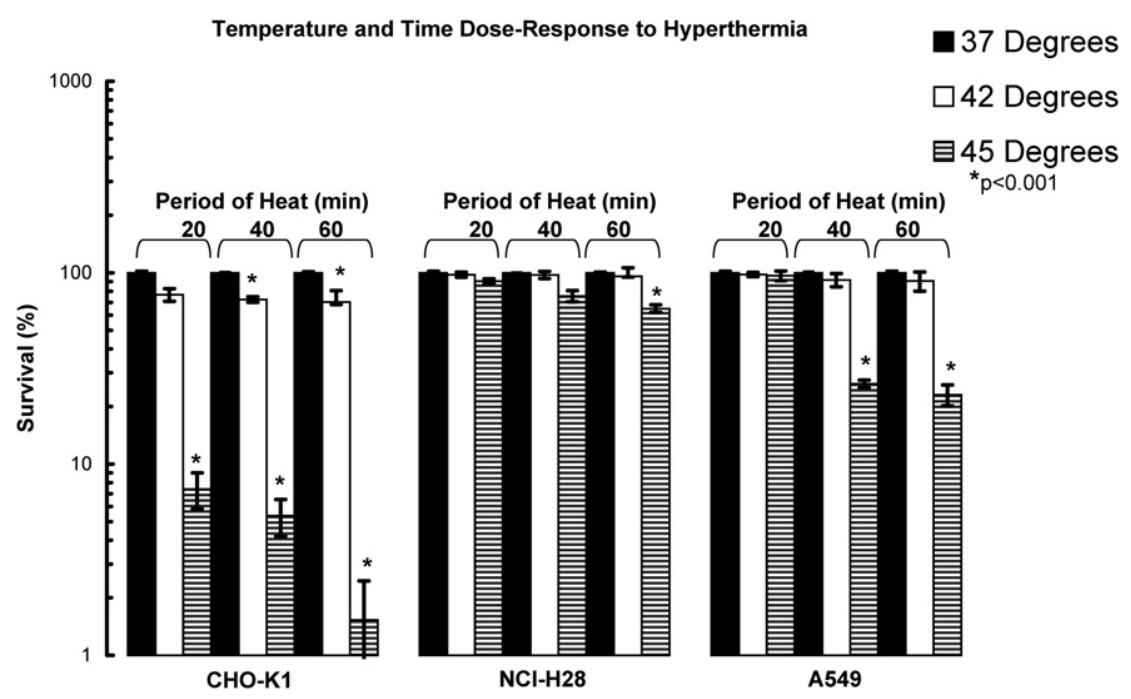

FIGURE 1. Dose-response relationship for time and temperature. The response of CHO-K1, NCI-H28, and A549 cell lines to varying degrees of heat $\left(37^{\circ} \mathrm{C}, 42^{\circ} \mathrm{C}\right.$, and $\left.45^{\circ} \mathrm{C}\right)$ for varying time periods $(0,20,40$, and 60 minutes) is shown. The $t$ test statistics are included where the results were statistically significant compared with the no treatment control cultures at a $P$ value less than .001 . $C H O$, Chinese hamster ovary.

\section{RESULTS}

\section{Assay Selection}

We initially evaluated and compared 2 different assays designed to determine cell viability after in vitro exposure to hyperthermia: an MTS metabolic assay and the more traditional clonogenic assay. In numerous repeated experiments, we exposed NCI-H28 and the known hyperthermia-sensitive $\mathrm{CHO}-\mathrm{K} 1$ cell lines to temperatures of $37^{\circ} \mathrm{C}, 42^{\circ} \mathrm{C}$, and $45^{\circ} \mathrm{C}$ for $0,20,40$, and $60 \mathrm{~min}-$ utes, respectively. Each assay was then run in parallel with both cell lines. The clonogenic assay consistently demonstrated diminished cell viability as measured by clonogenic potential after heat exposure, whereas the MTS assay showed no detectable differences among the experimental conditions (data not shown). The initial MTS assays were performed 4 to 24 hours after hyperthermia treatment, but to be certain that our timing was not an issue, we performed additional experiments with MTS assay time points of 24, 48, 72, 96, 168, and 192 hours after heating. All failed to show any difference in the MTS assay (data not shown). Thereafter for the remaining experiments reported in this article, we abandoned the use of MTS in favor of the more traditional clonogenic assay.

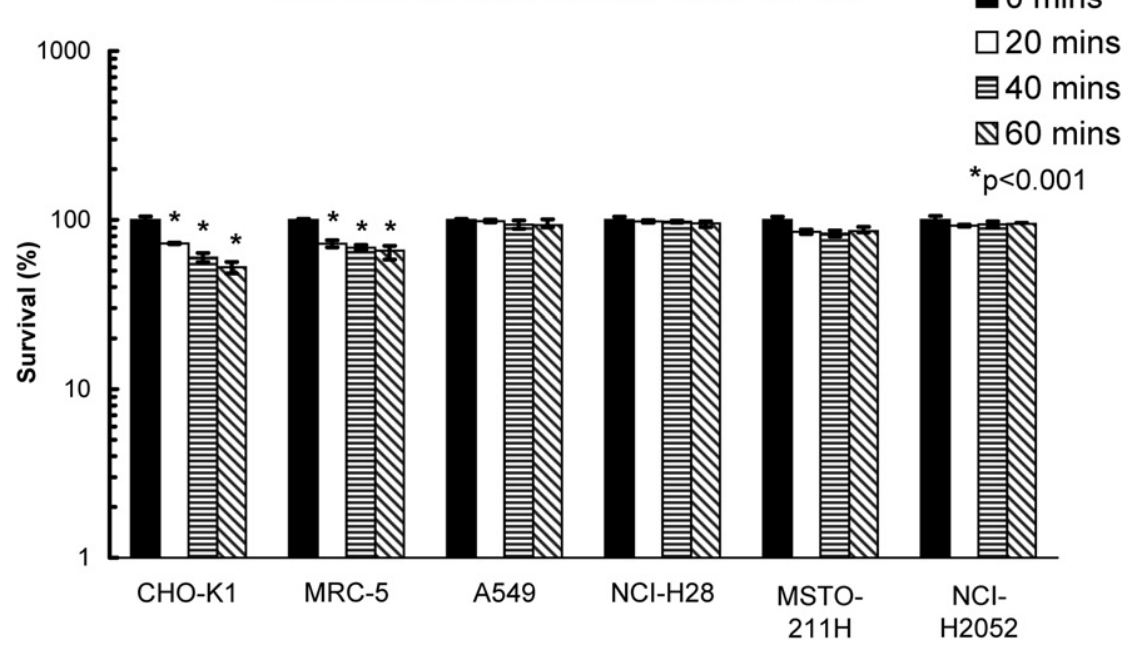

FIGURE 2. Dose-response relationship for time at $42^{\circ} \mathrm{C}$ for various cell lines. The response of CHO-K1, MRC-5, A549, NCI-H28, NCI-H2052, and MSTO- $211 \mathrm{H}$ cell lines to varying time periods $\left(0,20,40\right.$, and 60 minutes) at $42^{\circ} \mathrm{C}$ is shown. The $t$ test statistics are included where the results were statistically significant compared with the no treatment control cultures at a $P$ value less than .001 . $C H O$, Chinese hamster ovary. 


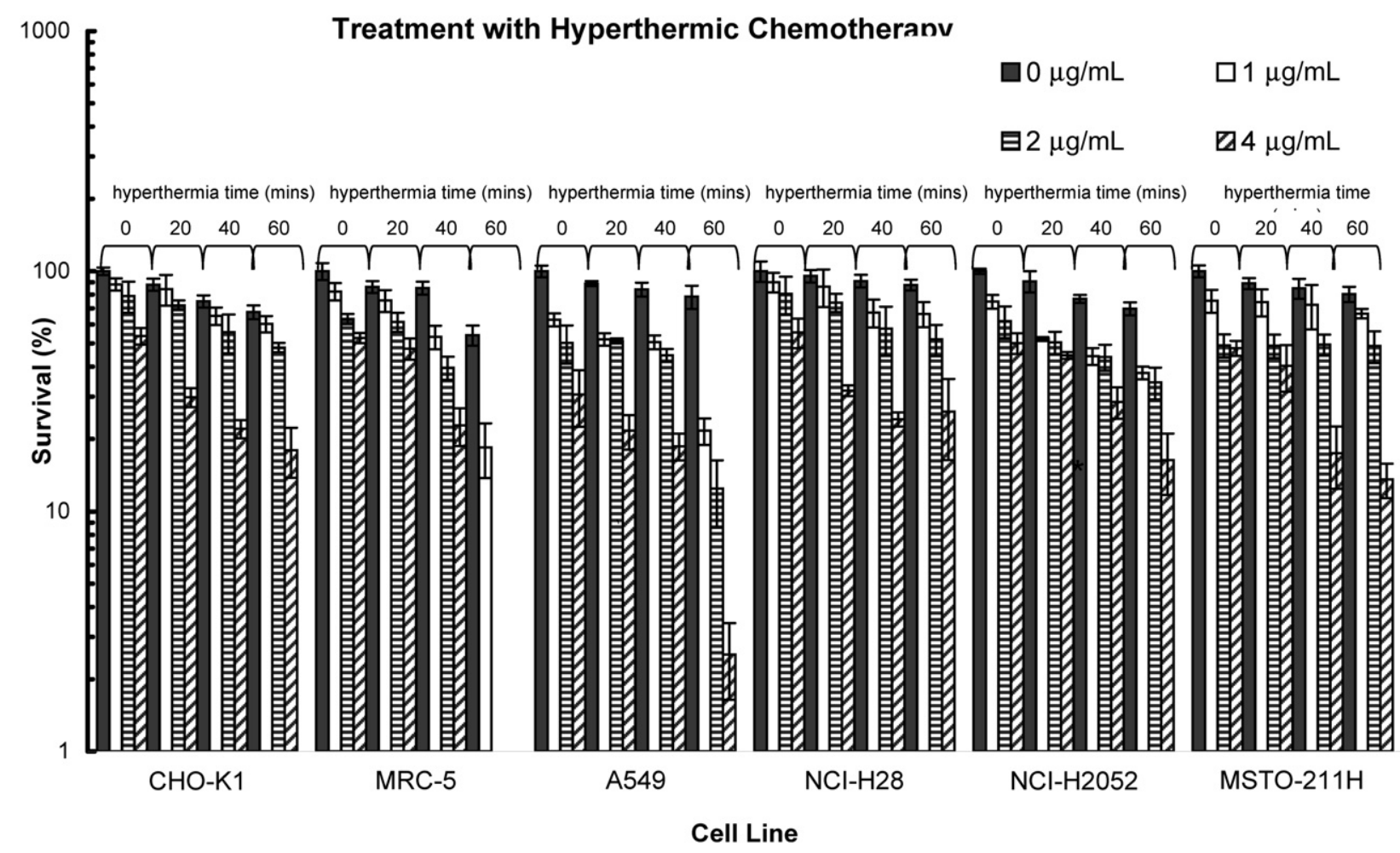

FIGURE 3. Hyperthermic chemotherapy with cisplatin. The response of CHO-K1, MRC-5, A549, NCI-H28, NCI-H2052, and MSTO-211H cell lines to varying doses of cisplatin chemotherapy combined with hyperthermia $\left(42^{\circ} \mathrm{C}\right)$ is shown. Of note, the reduction of cell viability mediated by chemotherapy (variation between different shaded bars) was greater than that seen with hyperthermia (variation between similar shaded bars). Although almost all findings were "statistically significant," the differences would be clinically meaningless. $\mathrm{CHO}$, Chinese hamster ovary.

\section{Temperature and Time-Dose Response}

First we investigated the effect of both length of heat exposure and exposure temperature on the survival of CHO-K1, A549, and NCI-H28 cell lines. The results of a representative experiment using temperatures of $37^{\circ} \mathrm{C}$, $42^{\circ} \mathrm{C}$, and $45^{\circ} \mathrm{C}$ for 20,40 , and 60 minutes, respectively, are shown in Figure 1. All cell lines showed a doseresponse to both temperature and time of hyperthermia with the survival of cells reproducibly and progressively reduced to $1.5 \% \pm 0.92 \%, 23.0 \% \pm 2.87 \%$, and $65.0 \% \pm$ $2.95 \%$ for the CHO-K1, A549, and mesothelioma NCIH28 cell lines, respectively (all $P<.001$ ). Although the effect of hyperthermia alone was considerable for all cell lines, the results were most consistent and greatest at $45^{\circ} \mathrm{C}$. Currently, clinical use of hyperthermia in mesothelioma almost exclusively is limited to temperatures $43^{\circ} \mathrm{C}$ or less, with temperatures from $41^{\circ} \mathrm{C}$ to $42^{\circ} \mathrm{C}$ the most common. Therefore, we repeated these experiments concentrating on the clinically relevant temperature of $42^{\circ} \mathrm{C}$ and tested a wider range of cell lines, including 2 additional mesothelioma cell lines: MSTO-211H and NCI-2072 (Figure 2). In this experiment, the statistically significant $(P<.001)$ but perhaps clinically insignificant reduction in the survival of CHO-K1 cells to $52.4 \% \pm 3.95 \%$ was again seen along with a reduction in the normal lung fibroblast cell line
MRC-5 to $65.8 \% \pm 4.27 \%(P<.001)$. The remaining cell lines, including all 3 mesothelioma cell lines, did not have a statistically meaningful reduction in survival even at the maximum time of 60 minutes at $42^{\circ} \mathrm{C}$.

\section{Cell Line Sensitivity to Heat}

We investigated the possibility that mesothelioma was particularly sensitive to heat treatment, as previously reported. $^{2}$ In Figure 1, the NCI-H28 human mesothelioma cell line was tested along with the A549 human lung cancer line, and although both had statistically significant reductions in cell survival after 40 and 60 minutes at $45^{\circ} \mathrm{C}$, the effect was more marked for the lung cancer cell line at both times $(P<.001)$. In Figure 2 , all 3 mesothelioma cell lines were heated for up to 60 minutes at $42^{\circ} \mathrm{C}$ without evidence of any effect despite the responsiveness of other cell lines under the same conditions in the same assay, such as the normal human lung fibroblast cell line MRC5 , which showed statistically decreased survival to $68.5 \% \pm 2.4 \%$ and $65.8 \% \pm 4.3 \%$ at 40 and 60 minutes, respectively $(P<.001)$. There is no suggestion in either of these 2 experiments that mesothelioma cell lines are particularly sensitive to hyperthermia when compared with other cell types. If anything, the results suggest that they may be more resistant. 

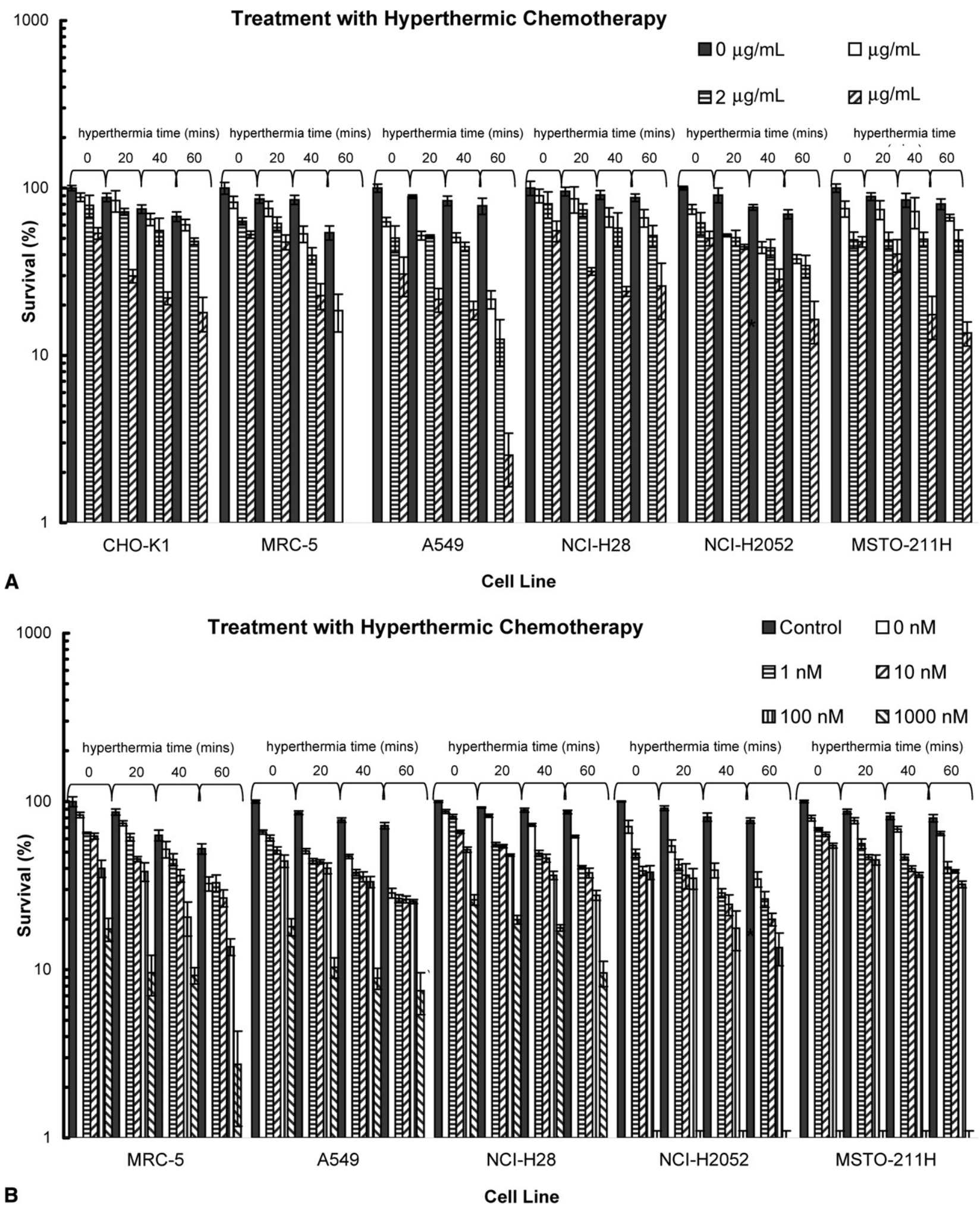

FIGURE 4. Hyperthermic chemotherapy with multiagent chemotherapy. The response of CHO-K1, MRC-5, A549, NCI-H28, NCI-H2052, and MSTO$211 \mathrm{H}$ cell lines to varying doses of combination chemotherapy with cisplatin + pemetrexed (A) or cisplatin + gemcitabine (B), both with hyperthermia, $\left(42^{\circ} \mathrm{C}\right)$ is shown. Of note, the reduction of cell viability mediated by chemotherapy (variation between different shaded bars) was greater than that seen with hyperthermia (variation between similar shaded bars). Although almost all findings were "statistically significant," the differences would be clinically meaningless. $\mathrm{CHO}$, Chinese hamster ovary. 


\section{Cisplatin Single-Agent Chemotherapy and Hyperthermia}

The combination of cisplatin and hyperthermia was investigated by the addition of varying concentrations of cisplatin $(1,2$, and $4 \mu \mathrm{g} / \mathrm{mL})$ as a single agent during heat exposure. These specific concentrations were chosen on the basis of pharmacokinetic data from prior studies showing a maximum blood/tissue level of approximately $200 \mathrm{ng} / \mathrm{mL}$ for intrapleural cisplatin instillation. ${ }^{8}$ Our levels exceeded the existing data by a factor of 50 and were thought to most accurately reflect attainable tumor tissue levels in vivo. The results (Figure 3) show a dose-response relationship for cisplatin, with increasing cisplatin levels producing decreasing cell survival. At maximum cisplatin concentration $(100 \mu \mathrm{g} /$ $\mathrm{mL}$ ), maximum temperature $\left(42^{\circ} \mathrm{C}\right)$, and maximum time (60 minutes), the clonogenic potential of the 3 mesothelioma cell lines (NCI-H28, NCI-H2052, and MSTO-211H) was modestly reduced to $26 \%, 16.4 \%$, and $13.6 \%$, respectively $(P<.01)$. The level of hyperthermia used in this experiment is equivalent to that most commonly used in clinical practice, but when the level was analyzed separately, a further reduction of only $29.6 \%, 33.8 \%$, and $34.2 \%$, respectively, was produced from the use of cisplatin alone. Therefore, the greatest proportion of the reduction in cell viability was attributable to chemotherapy and not to hyperthermia.

\section{Combination Chemotherapy and Hyperthermia}

The addition of combination chemotherapy to hyperthermia was investigated using 2 clinically active drug combinations: cisplatin and pemetrexed (Figure 4, A), and cisplatin and gemcitabine (Figure 4, B). With combinations of cisplatin/gemcitabine and cisplatin/pemetrexed, the reduction in cellular viability was greater than with the single-agent cisplatin alone. For the 3 mesothelioma cell lines (NCI-H28, NCI-H2052, and MSTO-211H), cisplatin and gemcitabine reduced cell survival to $9.6 \%, 0 \%$, and $0 \%$, respectively $(P<.01)$, and cisplatin and pemetrexed reduced the clonogenic potential to $0 \%, 7.2 \%$, and $4.5 \%$, respectively $(P<.01)$. The contributions of hyperthermia to the reduction in cellular viability among the 3 mesothelioma cell lines, however, was only $16.5 \%, 0 \%$, and $0 \%$, respectively, for the combination of cisplatin and gemcitabine and only $17.1 \%, 28.4 \%$, and $22.8 \%$, respectively, for the combination of cisplatin and pemetrexed (Table 1).

\section{DISCUSSION}

Hyperthermia with and without chemotherapy has been proposed as an intraoperative adjunct to surgical resection, whether lung-sparing pleurectomy or extra-pleural pneumonectomy. Enthusiasm for this treatment approach, in part, stems from the belief that tumors cell in general and mesothelioma cells in particular are sensitive to the combination of heat and chemotherapy. ${ }^{2,9}$ Woo and colleagues ${ }^{2}$ documented a difference in heat sensitivity of various tumors, with mesothelioma being the most sensitive. However, Woo and colleagues' study used freshly harvested tumor pieces and not established cell lines as in our studies. Fresh tumors are not pure cell populations and include a wide variety of contaminating cells, which can yield conflicting results. Furthermore, many fresh mesothelioma tumors do not quickly or easily adapt to in vitro culture, and when hyperthermia is added to the conditions during the transition period, the resulting data may incorrectly attribute a general loss of cell viability to that specifically due to hyperthermia. Although our data (Figures 1 and 2) do show a temperature- and time-dependent reduction in cellular viability, the mesothelioma cell lines demonstrate no particular sensitivity to hyperthermia and, in fact, seem more resistant to the effects of heat when compared with A549, a human lung cancer cell line, and MRC-5, a human lung fibroblast cell line.

One incidental finding from our study was that the MTS assay, which measures cellular metabolism, was unreliable for measuring changes in cellular viability after hyperthermia treatment, particularly when compared with a traditional clonogenic assay. Possible explanations include a neutralizing increase in metabolism due to the induction of thermotolerance and "heat shock" metabolic activity that balanced the opposing decrease in metabolic activity due to diminished cellular viability. However, the true reason for this finding remains unclear.

Despite the determined use of intraoperative hyperthermic chemotherapy at some mesothelioma treatment centers, no true level I/II evidence exists to support its current use. It is precisely this lack of definitive basic scientific and clinical data that accounts for the considerable variations in treatment details in clinical reports to date. For instance, there is no consensus as to the temperature required or the length of exposure time necessary for optimal effectiveness. Perfusate temperatures vary primarily from $39^{\circ} \mathrm{C}$ to $43^{\circ} \mathrm{C}$, with many surgeons currently targeting a perfusate temperature of $41.5^{\circ} \mathrm{C}$ to $42^{\circ} \mathrm{C}$, often by simply using a cardiopulmonary perfusion circuit and heat exchanger with limited heating capabilities. Our data (Figures 1 and 2) are consistent with previous basic hyperthermia research findings, which suggest that temperature elevations limited to modest levels (ie, $<43^{\circ} \mathrm{C}$ ) are associated with a limited effectiveness of hyperthermia compared with temperatures of $44^{\circ} \mathrm{C}$ to $45^{\circ} \mathrm{C}$ or higher. ${ }^{9}$ One likely factor at least partially accounting for this observation is that cells heated to temperatures less than $43^{\circ} \mathrm{C}$ (compared with higher temperatures) develop thermotolerance simultaneously with heating, ${ }^{10,11}$ a phenomenon that explains the change in the slope at $43^{\circ} \mathrm{C}$ of the line depicting the energy required for cellular inactivation versus temperature (Arrhenius analysis) with temperatures less than $43^{\circ} \mathrm{C}$ requiring increased energy for cellular inactivation. ${ }^{12}$ One 
TABLE 1. Specific proportional reduction in cell viability mediated by hyperthermia in multiagent hyperthermic chemotherapy

\begin{tabular}{|c|c|c|c|c|c|c|c|}
\hline \multirow[b]{2}{*}{ Cell line } & \multirow[b]{2}{*}{ Time (min) } & \multicolumn{6}{|c|}{ Pemetrexed $(\mu \mathrm{g} / \mathrm{mL})$} \\
\hline & & Heat alone & $\mathbf{0}$ & 0.1 & 1 & 10 & 100 \\
\hline \multirow[t]{3}{*}{ MRC-5 } & 20 & $18.48 \pm 4.65$ & $9.14 \pm 4.58$ & $4.19 \pm 3.57$ & $12.76 \pm 4.05$ & $27.05 \pm 2.06$ & $33.71 \pm 1.14$ \\
\hline & 40 & $36.57 \pm 6.01$ & $25.90 \pm 2.87$ & $45.52 \pm 4.93$ & $43.24 \pm 2.01$ & $40.19 \pm 3.75$ & $39.24 \pm 0.66$ \\
\hline & 60 & $52.76 \pm 1.19$ & $52.00 \pm 2.31$ & $51.05 \pm 2.16$ & $47.24 \pm 1.19$ & $46.67 \pm 2.31$ & $44.38 \pm 1.19$ \\
\hline \multirow[t]{3}{*}{ A549 } & 20 & $14.20 \pm 1.30$ & $12.21 \pm 0.91$ & $5.96 \pm 1.80$ & $2.98 \pm 1.53$ & $2.38 \pm 2.69$ & $2.98 \pm 1.24$ \\
\hline & 40 & $20.95 \pm 2.53$ & $15.69 \pm 1.13$ & $8.94 \pm 2.43$ & $8.34 \pm 2.28$ & $7.55 \pm 1.19$ & $5.76 \pm 0.60$ \\
\hline & 60 & $29.20 \pm 1.24$ & $41.11 \pm 0.75$ & $18.47 \pm 1.94$ & $15.59 \pm 2.55$ & $10.92 \pm 0.34$ & $7.75 \pm 0.34$ \\
\hline \multirow[t]{3}{*}{ NCI-H28 } & 20 & $9.76 \pm 3.37$ & $6.34 \pm 6.92$ & $11.71 \pm 4.39$ & $8.29 \pm 2.24$ & $6.34 \pm 2.24$ & $12.20 \pm 1.46$ \\
\hline & 40 & $14.15 \pm 3.05$ & $18.05 \pm 5.14$ & $14.63 \pm 4.39$ & $20.98 \pm 5.07$ & $20.98 \pm 2.24$ & $31.68 \pm 0.01$ \\
\hline & 60 & $17.07 \pm 3.05$ & $20.49 \pm 3.87$ & $25.37 \pm 5.14$ & $36.59 \pm 2.24$ & $31.22 \pm 1.69$ & $31.68 \pm 0.01$ \\
\hline \multirow[t]{3}{*}{ NCI-H2052 } & 20 & $8.70 \pm 2.03$ & $21.48 \pm 3.46$ & $17.39 \pm 2.69$ & $20.97 \pm 2.69$ & $16.62 \pm 4.36$ & $20.46 \pm 1.93$ \\
\hline & 40 & $20.20 \pm 5.03$ & $36.83 \pm 1.60$ & $29.67 \pm 1.93$ & $30.18 \pm 4.23$ & $24.55 \pm 3.19$ & $25.58 \pm 2.34$ \\
\hline & 60 & $28.39 \pm 2.47$ & $41.18 \pm 2.03$ & $37.85 \pm 1.60$ & $36.32 \pm 2.47$ & $29.67 \pm 1.93$ & $29.67 \pm 1.17$ \\
\hline \multirow[t]{3}{*}{ MSTO-211H } & 20 & $11.26 \pm 1.74$ & $6.21 \pm 2.11$ & $3.91 \pm 2.42$ & $10.57 \pm 3.16$ & $5.52 \pm 1.05$ & $8.62 \pm 0.49$ \\
\hline & 40 & $19.08 \pm 3.26$ & $15.17 \pm 3.11$ & $20.00 \pm 4.04$ & $25.98 \pm 1.74$ & $10.34 \pm 1.05$ & $11.72 \pm 0.98$ \\
\hline & 60 & $22.76 \pm 4.52$ & $20.00 \pm 2.87$ & $24.14 \pm 2.79$ & $43.22 \pm 1.05$ & $15.17 \pm 1.05$ & $12.76 \pm 0.49$ \\
\hline
\end{tabular}

This table quantifies the additional proportional reduction in cellular viability of CHO-K1, MRC-5, A549, NCI-H28, NCI-H2052, and MSTO-211H cell lines specifically mediated by hyperthermia in varying combination chemotherapy conditions. Although many findings were "statistically significant," the additional benefit of hyperthermia was modest and observed primarily at the longer time intervals.

mechanism recently proposed to explain the development of this thermotolerance involves upregulation of $\mathrm{Hsp} 40 /$ Hsp70 expression at temperatures less than $43^{\circ} \mathrm{C}^{13}$

The issue of temperature is complicated further by the general absence of tissue temperature as an end point in clinical reports. Perfusate temperatures (inlet or outlet) as surrogates for intrapleural temperatures almost invariably are recorded and do not necessarily reflect the critical tissue temperatures in the chest wall, mediastinum, and lung. Organ/tissue temperatures, when reported, have been limited to esophageal, rectal, and pulmonary artery temperatures, which consistently are $39.5^{\circ} \mathrm{C}$ or less, ${ }^{14}$ no higher than a postoperative fever after talc pleurodesis.

The length of hyperthermia time also is fairly arbitrary, ranging from 30 to 120 minutes in clinical reports. Our data in Figure 1 show that increasing hyperthermia time to 60 minutes decreases cell survival in all cell lines, including the normal lung fibroblast cell line MRC-5. Together with our temperature data, this suggests that the optimal conditions for intraoperative hyperthermia would most likely include exposure to at least $45^{\circ} \mathrm{C}$ for 60 minutes or more. However, the toxicity of these levels of hyperthermia in vivo is unknown, and it may be strategically more successful to use higher temperatures (ie, $45^{\circ} \mathrm{C}-46^{\circ} \mathrm{C}$ ) (possibly with newer perfusion circuits ${ }^{15}$ ) and shorter time intervals (ie, 20-40 minutes). As shown in Figure $1,45^{\circ} \mathrm{C}$ for 40 minutes produced superior results compared with $42^{\circ} \mathrm{C}$ for 60 minutes in all cell lines.

Multiagent chemotherapy predictably is better than monotherapy (Figure 4). Of note, any effectiveness of hyperthermia seemed to decrease with increasing chemotherapy efficacy. In all cases, hyperthermia at clinically relevant levels (ie, $42^{\circ} \mathrm{C}$ for 60 minutes) only augmented the effectiveness of the multiagent platinum-based chemotherapy combinations between $0 \%$ and $28.4 \%$.

There are limitations to in vitro assays in determining the effect of hyperthermia on cancer cells in vivo. For instance, the treatment of cell monolayers does not necessarily predict results using 3-dimensional tumor/normal tissues and intact vascularized solid tumor areas, in particular. Furthermore, hyperthermia-induced inflammatory cascades, immune responses, and vascular permeability, as well as other changes, are not present, cannot be measured, and may be complicated or even overwhelmed by additional changes in these parameters induced by the surgical procedure itself. Yet, intraoperative hyperthermic perfusion optimally is applied to minimal residual superficial disease, which at least ostensibly, does somewhat resemble tissue culture conditions.

Yet another issue regarding the effectiveness of intracavitary hyperthermia is the well-documented "heat sink" effect of areas of large blood vessels/flow. ${ }^{16-19}$ With the large blood flow through the mediastinum, lung, upper extremity/thoracic outlet, and liver/spleen/organs below the diaphragm, the ability of the chest cavity to act as a radiator and dissipate heat can be a daunting challenge. Despite measuring an inlet and outlet temperature of $42^{\circ} \mathrm{C}$, the effective temperature at the tissue level may be far less, thereby further compromising the utility of hyperthermia therapy. Few researchers document the actual tissue temperature with temperature probes and when done show only an extremely modest effect in the esophagus and pulmonary blood of the lung $\left(\leq 38.6^{\circ} \mathrm{C}\right){ }^{20}$ Thus, the current clinical practice using perfusate temperatures of $42^{\circ} \mathrm{C}$ for 60 minutes clearly may not be optimal, but the ideal hyperthermia time and temperature remain to be 
TABLE 1. Continued

\begin{tabular}{|c|c|c|c|c|c|}
\hline \multicolumn{6}{|c|}{ Gemcitabine (nM/mL) } \\
\hline Heat alone & $\mathbf{0}$ & 1 & 10 & 100 & 1000 \\
\hline $13.36 \pm 3.61$ & $8.90 \pm 2.59$ & $3.77 \pm 3.14$ & $16.78 \pm 1.57$ & $1.71 \pm 4.86$ & $7.88 \pm 2.59$ \\
\hline $36.99 \pm 4.63$ & $31.16 \pm 5.84$ & $19.86 \pm 3.71$ & $26.03 \pm 3.14$ & $19.52 \pm 4.71$ & $8.22 \pm 1.03$ \\
\hline $47.60 \pm 3.70$ & $50.68 \pm 3.14$ & $32.19 \pm 3.71$ & $35.62 \pm 3.08$ & $26.37 \pm 1.57$ & $14.73 \pm 1.57$ \\
\hline $14.23 \pm 2.14$ & $15.09 \pm 1.74$ & $16.22 \pm 1.48$ & $7.40 \pm 1.24$ & $4.17 \pm 2.96$ & $7.69 \pm 1.43$ \\
\hline $22.39 \pm 2.42$ & $18.69 \pm 1.35$ & $22.77 \pm 1.58$ & $15.46 \pm 2.42$ & $11.01 \pm 2.56$ & $9.11 \pm 1.28$ \\
\hline $28.08 \pm 3.12$ & $37.29 \pm 1.90$ & $34.16 \pm 1.48$ & $25.05 \pm 1.24$ & $18.88 \pm 0.72$ & $10.53 \pm 2.10$ \\
\hline $7.89 \pm 0.74$ & $5.03 \pm 1.81$ & $25.84 \pm 1.63$ & $11.83 \pm 1.20$ & $3.75 \pm 0.74$ & $6.21 \pm 1.18$ \\
\hline $11.14 \pm 2.46$ & $14.60 \pm 1.36$ & $32.15 \pm 1.97$ & $20.02 \pm 2.52$ & $15.38 \pm 2.07$ & $8.28 \pm 0.78$ \\
\hline $13.41 \pm 2.10$ & $25.44 \pm 1.04$ & $40.73 \pm 0.95$ & $28.40 \pm 2.52$ & $24.06 \pm 1.90$ & $16.47 \pm 1.63$ \\
\hline $8.65 \pm 2.98$ & $16.54 \pm 4.56$ & $7.14 \pm 3.26$ & $2.26 \pm 6.21$ & $3.01 \pm 4.92$ & $<0.01 \pm 0.01$ \\
\hline $19.17 \pm 4.56$ & $31.95 \pm 3.96$ & $20.68 \pm 1.72$ & $14.29 \pm 3.45$ & $20.30 \pm 4.70$ & $<0.01 \pm 0.01$ \\
\hline $22.93 \pm 2.84$ & $36.47 \pm 3.63$ & $22.93 \pm 2.84$ & $18.80 \pm 1.72$ & $24.44 \pm 2.98$ & $<0.01 \pm 0.01$ \\
\hline $12.83 \pm 2.81$ & $2.72 \pm 3.11$ & $12.50 \pm 3.75$ & $17.07 \pm 1.54$ & $9.67 \pm 3.11$ & $<0.01 \pm 0.01$ \\
\hline $18.26 \pm 3.61$ & $11.09 \pm 2.62$ & $22.07 \pm 1.82$ & $23.91 \pm 1.54$ & $18.04 \pm 1.23$ & $<0.01 \pm 0.01$ \\
\hline $20.33 \pm 3.98$ & $15.11 \pm 1.82$ & $28.04 \pm 3.33$ & $25.33 \pm 0.86$ & $22.50 \pm 1.47$ & $<0.01 \pm 0.01$ \\
\hline
\end{tabular}

determined and likely will require carefully planned prospective randomized clinical trials.

The pleural space after complete pleurectomy or even extrapleural pneumonectomy offers a huge absorptive surface that produces systemic blood levels of chemotherapy agents that are similar to those seen when similar doses are given intravenously. ${ }^{8}$ Because of this massive absorptive surface, the large differential concentrations of chemotherapy locally in the chest compared with blood/systemic levels are not as great as in the peritoneum, where a greater proportion of the mesothelial surface remains intact to prevent rapid absorption of the instilled chemotherapy agents. This is particularly true when hyperthermia and chemotherapy are combined. ${ }^{7}$ The large blood flow through the mediastinum and lung also acts to efficiently absorb any drug(s) in the chest and rapidly distribute them systemically.

The modest level of increased cytotoxicity mediated by hyperthermia (Figures 3 and 4, $A$ and $B$, and Table 1 ) would most likely be clinically meaningless in the log-kill (Skipper-Schabel-Wilcox) model of cancer exponential growth kinetics, which requires several "log kills" to even approach an effectiveness level that is clinically detectable and meaningful. ${ }^{21,22}$

\section{CONCLUSIONS}

Our data demonstrate that hyperthermia and chemotherapy have a dose response (temperature and time) as measured in mesothelioma cell lines, but the general perception that mesothelioma is a heat-sensitive tumor is not supported by our data. Further, the level of hyperthermia required for clinically relevant cytotoxicity is likely to be $45^{\circ} \mathrm{C}$ or greater. Other findings are that multiagent chemotherapy seems to have tremendous benefit over single-agent therapy and that the greater the effect of chemotherapy, the smaller the apparent benefit of hyperthermia. Taken together, these data suggest that the current practice of pleural perfusion at $42^{\circ} \mathrm{C}$ for 1 hour often with single-agent cisplatin is likely ineffective and that the optimal target for intraoperative hyperthermic chemotherapy perfusion would use combinations of chemotherapy agents, such as cisplatin and pemetrexed or cisplatin and gemcitabine, at $45^{\circ} \mathrm{C}$ or greater for 60 minutes or more, if tolerated on the basis of clinical toxicity. Even with these data, randomized prospective clinical trials are warranted before any conclusions can be made regarding the efficacy of this largely theoretic approach to cancer treatment in patients with mesothelioma.

\section{References}

1. Storm FK, Elliott RS, Harrison WH, Kaiser LR, Morton DL. Radio frequency hyperthermia of advanced human sarcomas. J Surg Oncol. 1981;17:91-8.

2. Woo SY, Rice GC, Kapp DS, Hahn GM. A predictive assay for human tumor cellular response to hyperthermia using dansyl lysine staining and flow cytometry. Int J Radiat Oncol Biol Phys. 1988;14:361-5.

3. Giovanella BC, Stehlin JS Jr, Morgan AC. Selective lethal effect of supranorma temperatures on human neoplastic cells. Cancer Res. 1976;36(11 Pt 1):3944-50.

4. Lang-Lazdunski L, Bille A, Belcher E, Cane P, Landau D, Steele J, et al. Pleurectomy/decortication, hyperthermic pleural lavage with povidone-iodine followed by adjuvant chemotherapy in patients with malignant pleural mesothelioma. J Thorac Oncol. 2011;6:1746-52.

5. Tilleman TR, Richards WG, Zellos L, Johnson BE, Jaklitsch MT, Mueller J, et al Extrapleural pneumonectomy followed by intracavitary intraoperative hyperthermic cisplatin with pharmacologic cytoprotection for treatment of malignant pleural mesothelioma: a phase II prospective study. J Thorac Cardiovasc Surg. 2009; 138:405-11.

6. de Bree E, van Ruth S, Schotborgh CE, Baas P, Zoetmulder FA. Limited cardiotoxicity after extensive thoracic surgery and intraoperative hyperthermic intrathoracic chemotherapy with doxorubicin and cisplatin. Ann Surg Oncol. 2007; 14:3019-26

7. Ratto GB, Civalleri D, Esposito M, Spessa E, Alloisio A, De Cian F, et al. Pleural space perfusion with cisplatin in the multimodality treatment of malignant mesothelioma: a feasibility and pharmacokinetic study. J Thorac Cardiovasc Surg. 1999;117:759-65. 
8. Rusch VW, Niedzwiecki D, Tao Y, Menendez-Botet C, Dnistrian A, Kelsen D, et al. Intrapleural cisplatin and mitomycin for malignant mesothelioma following pleurectomy: pharmacokinetic studies. J Clin Oncol. 1992;10:1001-6.

9. Hahn GM, Braun J, Har-Kedar I. Thermochemotherapy: synergism between hyperthermia (42-43 degrees) and adriamycin (of bleomycin) in mammalian cell inactivation. Proc Natl Acad Sci U S A. 1975;72:937-40.

10. Li GC, Hahn GM. A proposed operational model of thermotolerance based on effects of nutrients and the initial treatment temperature. Cancer Res. 1980;40:4501-8.

11. Meyer JL, Kapp DS, Fessenden P, Hahn GH. Hyperthermic oncology: current biology, physics and clinical results. Pharmacol Ther. 1989;42:251-88.

12. Li GC, Cameron RB, Sapareto SA, Hahn GM. Reinterpretation of Arrhenius analysis of cell inactivation by heat. NCI Monogr. 1982;61:111-3.

13. Roth M, Zhong J, Tamm M, Szilard J. Mesothelioma cells escape heat stress by upregulating Hsp40/Hsp70 expression via mitogen-activated protein kinases. J Biomed Biotechnol. 2009;2009:451084. Epub 2009 Jun 17.

14. de Bree E, van Ruth S, Baas P, Rutgers EJ, van Zandwijk N, Witkamp AJ, et al. Cytoreductive surgery and intraoperative hyperthermic intrathoracic chemotherapy in patients with malignant pleural mesothelioma or pleural metastases of thymoma. Chest. 2002;121:480-7.

15. Riley W. Belmont Hyperthermia Pump in the conduct of intra-operative heated chemotherapy. Perfusion. 2009;24:115-8.
16. Lu DS, Raman SS, Vodopich DJ, Wang M, Sayre J, Lassman C. Effect of vessel size on creation of hepatic radiofrequency lesions in pigs: assessment of the "heat sink" effect. AJR Am J Roentgenol. 2002;178:47-51.

17. Kolios MC, Sherar MD, Hunt JW. Large blood vessel cooling in heated tissues: a numerical study. Phys Med Biol. 1995;40:477-94.

18. Crezee J, Mooibroek J, Lagendijk JJ, van Leeuwen GM. The theoretical and experimental evaluation of the heat balance in perfused tissue. Phys Med Biol. 1994;39:813-32.

19. Crezee J, Lagendijk JJ. Experimental verification of bioheat transfer theories: measurement of temperature profiles around large artificial vessels in perfused tissue. Phys Med Biol. 1990;35:905-23.

20. Fujimura T, Yonemura Y, Nojima N, Nakai M, Kaji M, Sahara H, et al. Intrathoracic hyperthermochemotherapeutic perfusion for the intrathoracic malignancies in gastric cancer. Hepatogastroenterology. 1995;42:878-84.

21. Wilcox WS, Griswold DP, Laster WR Jr, Schabel FM Jr, Skipper HE. Experimental evaluation of potential anticancer agents. XVII. Kinetics of growth and regression after treatment of certain solid tumors. Cancer Chemother Rep. 1965;47: 27-39.

22. Skipper HE, Schabel FM Jr, Wilcos WS. Experimental evaluation of potential anticancer agents. XIII. On the criteria and kinetics associated with "curability" of experimental leukemia. Cancer Chemother Rep. 1964;35:1-111. 